Review Article

\section{The sugarcane byproducts to a food security in an ecofriendly way: A review}

\author{
Oscar Almazán del Olmo* and Indira Pérez
}

Cuban Research Institute of Sugarcane Derivatives (ICIDCA), Cuba

\section{Abstract}

This article addresses, in an integrated way, the main aspects of the by-products obtained from sugarcane processing summarizing their most important and economic characteristics, their composition, and most relevant uses as options for industrial diversification, all taken as a review.

\section{Introduction}

The Sugar cane byproducts are a huge field of knowledge, of industrial alternatives, of economic possibilities and also an important part of a base of an appealing, fair and possible world for the human race.

Because of this, it's beyond the limits of an article like this to cover them in full; alternatively, a single line was selected, to be evaluated to some extent, but never pretending to exhaust it and its entourage.

The selected line is one of the paramount challenges the human beings must overcome: food security; being always open to analyze other lines of the sugar cane byproducts, in future articles, if desired and demanded.

First and foremost, let us celebrate the sugar cane plant, simply a reed but which, owing to its capacity to utilize water, solar energy and carbon dioxide, to synthesize a sweet substance called sucrose, is totally different from a large number of its brothers and relatives in the plant kingdom.

The British writer, Henry Hobhouse, author of the bestseller Seed of Change, has described sugar cane as one of the six plant species which have transformed humanity, among the others are tea, cotton and potato. I may not agree with some of the various points raised by him in his book, but we must recognize that sugar cane is much more than a sweet stalk.

From its origin in New Guinea, transported by marine currents, has been cultivated throughout of South East Asia slavery. cultivation $[1,2]$.

\section{More Information}

*Address for Correspondence:

Dr. Cs. Oscar Almazán del Olmo PhD, Cuban Research Institute of Sugarcane Derivatives (ICIDCA), Email: oscarao@ceniai.inf.cu; indira.perez@icidca.azcuba.cu; oscar.almazan@icidca.azcuba.cu

Submitted: December 16, 2021

Approved: January 03, 2022

Published: January 04, 2022

How to cite this article: del Olmo OA, Pérez I. The sugarcane byproducts to a food security in an ecofriendly way: A review. Arch Food Nutr Sci. 2022; 6: 001-005.

DOI: 10.29328/journal.afns. 1001031

ORCiD: orcid.org/000-0002-1876-2474

Copyright License: (c) 2022 del Olmo OA, et al. This is an open access article distributed under the Creative Commons Attribution License, which permits unrestricted use, distribution, and reproduction in any medium, provided the original work is properly cited.

\section{W) Check for updates}

OPEn ACCEss

well before the Christian era, largely utilized in ancient India 1000 years BC; sugar itself was produced in the Indian State of Bihar 700 years BC and exported to China. It moved steadily toward the West and with the Arabs conquests sugar cane was present from Syria to Spain and on the Canary Islands, from where, in his first discovery trip, Christopher Columbus, took it to the island of "La Española". Extended rapidly in the Caribbean, Central, North and South America, its exploitation induced, in a great measure, the greatest migration which mankind had known, especially if taking into account the

Sugar cane has, therefore, shaped societies and there are countries that have been transformed by sugar cane

The impact of sugar cane today is still considerable, in a large number of countries and it would even be difficult to imagine many of them, in the tropics, without sugar cane [3].

It's not only a plant to make sugar, but it gives 20 times the energy used to cultivate it, has the capacity to sequester 19 tons of $\mathrm{HHG}$ /ha per year, being, also able to renew $100 \%$ in 12 months, embellished the scenery, hampers erosion and prevents migrations from rural to urban areas. It has deeply affected societies to the point of imprinting their arts and culture and even their folklore. 
We should not overlook the fact that sugar, is, with its 4 $\mathrm{Kcal} / \mathrm{g}$ and its natural psychological attraction, more than a sweetener and above all, an unrivaled and irreplaceable food, the purest, simple, healthy and cheapest source of food energy the human race can has, is especially true for that large share of humanity in developing countries.

It's clear that today, at the beginning of the $3^{\text {rd }}$ Millennium, almost 3.5 thousand million people are not getting the amount of food they need and deserve; even, maybe today, when we are reading this, for a child, a woman, an old man, somewhere, a spoonful of sugar, in a glass of water, could mean their only opportunity to remain alive. It could sound melodramatic, but unfortunately, it's shamefully true.

Therefore, sugar cane is, by no means, a simple plant species, is today, in the 21st century, an important factor of a bright future, not only because of sugar but because this most efficient bio-factory in the plant kingdom, holds promises, as the alternative to overcome hunger, a true way to ensure the badly needed food security.

Many are the options and opportunities sugar cane offers, alternatives of different technical levels, being the support of an efficient animal feeding system in the tropics, for the economies of insular tropical developing countries, where arable lands are one of the limiting factors.

The route of the byproducts of the sugar cane to food production, will guaranty not only a healthy diversification of the sugar industry, avoiding the dependence on one good, but ensuring the independence from a food world market, expensive and uncertain [4-6], a way to reach self-sufficiency, based on a crop well known, of real correspondence with the climate; all to get a solid background to support the social development.

When analyzing the sugar cane agro-industrial process, we find that when 100 tons of clean cane stalk are milled, 16 tons of trash or crop residues are left in the field and in the factory 11-12 tons of sugar are recovered, giving, also, as co-products:

- $\quad 28$ tons of bagasse with 50\% humidity.

- $\quad 3$ tons of blackstrap molasses with $88 \%$ dry matter.

- $\quad 3$ tons of filter cake with 75\% moisture.

Let's have a brief look at each one, their characteristics, composition and potentials.

\section{Bagasse}

Bagasse is the lignocellulosic residue from the milling of the cane stalk, obtained at the exit of the last roll mill in the milling tandem of the factory. It comprises a heterogeneous group of particles of different sizes that range from 1 to 25 $\mathrm{mm}$, with a mean size of $20 \mathrm{~mm}$.
The particle size distribution of bagasse depends mainly on the work of the cane preparation equipment and to a lesser extent on the design of the tandem's mill and the cane variety.

The physical composition of bagasse leaving the milling tandem is, in general, characterized by four fractions:

\begin{tabular}{|c|c|}
\hline & $\%$ \\
\hline Fiber or bagasse & 45 \\
\hline Insoluble solids & $02-03$ \\
\hline Soluble solids & $02-03$ \\
\hline Water & 50 \\
\hline
\end{tabular}

There is a trend in sugar factories to raise the level of cane preparation before milling, in order to maximize sugar extraction and to increase the capacity of the milling station. This practice may also be useful for the industries that use bagasse as raw material if the defibering is used rather than fiber cutting. This will allow getting higher efficiency in the pith removing stage, without affecting the length of the fibers. The organic solid part that is insoluble in water, which is present in the sugarcane stalk and has a wide range of chemical and morphological characteristics, is known as "the fiber". This fraction carries the structural elements.

Insoluble solids, due to their inorganic nature, are mainly composed of soil, stone and other alien components. This fraction, though small, influence bagasse composition and is influenced by the type of soil and crop traits.

The soluble solids are mainly composed of sucrose, remaining from the milling and lixiviation processes in the extraction station of the sugar factories, as well as other components like waxes, in very small amounts.

Bagasse has absorption and capillary mechanisms that favor water retention. This phenomenon plays an important role in certain technological processes in which the bagasse is used as raw material. It's clear that the soluble solid content and the moisture of bagasse depend on the operational variables of the sugar industry.

\section{Morphological profile of bagasse}

This aspect has a significant influence over the use of bagasse, as raw material, in different industrial processes and is directly related with that of the sugarcane, where the cortex fibers, the fibrovascular bundles and other fibrous forms are found giving resistance to the vegetable stalk. The parenchymatous tissue- responsible for the inner flow of the vital fluids and the site of storage of the sucrose, in the sugarcane stalk- is a non -fiber component, also present in bagasse and known as "pith".

Pith is usually removed in most of the derivatives industries due, among other reasons, to the serious inconvenience that carries to the processes, affecting the quality of the final products and the increase of the consumption index of 
chemicals, raising unnecessarily the costs of production. In the sugar factory part of the pith is separated, the fraction composed also of some fibers and microfibers, known as "bagacillo", is used as a filter aid in the sugar process and the excess is recirculated to the boilers or employed in animal feeding, enriched with some supplements and also processed to elevate its digestibility.

The bagasse fibers are characterized by their rigidity, with a mean length smaller than the one of the usual forest species; this is a limiting factor for some productions like the high resistant papers.

When analyzing the structure of the cane stalk, it is possible to identify a fine external layer that covers and protects, making it impermeable to the sugar juices, but containing nonessential components, classified in bagasse as extractives.

The cortex, that follows, is made of very lignified fibers, of greater length and rigidity, that protect the stalk from external biological and mechanical effects, being, actually, the support of the cane stalk.

The inner part of the sugarcane stalk is the already mentioned parenchymatous tissue, whose function is to store the sucrose juice; the fibrovascular bundles, comprised of fibers and vessels that contribute to carrying nutrients, salts and products up the stalk from the roots, are also within this tissue. This is the most attractive fraction for the production of animal feed.

But when the cane is milled, this anatomical order is disrupted from the structural point of view, and broken up into a mixed array of different particles, with the approximate distribution of Cortex long fibers (50\%), Parenchyma (30\%), fibrovascular vessels (15\%), Epidermal cells (5\%)

In general, the cortex and short fibers inside the stalk are known as a fraction named "fiber" or "useful fiber", the second portion made up of pith and a third one comprised of fines, soil and soluble.

The fiber content of the whole bagasse (dry base) is around $60 \%$, the pith account for $30 \%$ and the remaining $10 \%$ correspond to the aforementioned third fraction.

With the development of the mechanization of the cane crop and the introduction of new varieties, with high sugar content and low fiber, these values will be modified.

According to the extensive tests carry on in Cuba, it has been established that the parameters characterizing the bagasse leaving the last mill of a tandem are as follow:

\begin{tabular}{|c|c|}
\hline & Range (\%) \\
\hline Fraction & $55-60$ \\
\hline Fiber & $30-35$ \\
\hline Pith & $02-\mathrm{Mar}$ \\
\hline Fines, soil, soluble & $10-15$ \\
\hline
\end{tabular}

The chemical composition of bagasse shows that it is composed of cellulose, hemicelluloses and lignin, as its main natural polymers. It also has small amounts of other components, generally classified as foreign matters.

The most frequent chemical composition of whole bagasse gives a $48 \%$ of cellulose, $29 \%$ of pentosans and $23 \%$ of lignin.

The experimental studies confirm that the chemical composition of bagasse is not affected, to a great extent, by the variety of cane.

Cellulose is the main component of the cells walls of the plant. The fact that it is insoluble in water, in organic solvents and in alkaline solutions, in addition to its resistance to the effects of oxidizing agents, distinguishes cellulose from the rest of the chemical components of bagasse and other biomasses.

Chemically, cellulose is defined as a homopolymer of D-glucose, whose main link to the other units in the chain is of the $\beta$ 1-4 type, with a molecular weight that ranges between 150000 and 350000.

Hemicelluloses cover a series of various polysaccharides, which are soluble in solvents, react to acids and are decomposed in sugars and furfural. The hemicelluloses that are predominant in bagasse are of the D-xylene type. The polymer chains are short; the average viscometric molecular weight is within a range of 10000 to 20000 and the proportions are from $25 \%$ to $27 \%$.

Lignin is the third most important component of bagasse in so far as quantity is concerned - from $20 \%$ to $25 \%$ - and includes a series of amorphous reticularpolymers with a high molecular weight and basically phenolic in nature.

\section{Bagasse storage}

Bagasse is available only during the sugar campaign or season, which in most countries lasts for only four to five months. Thus the plant that uses bagasse as a raw material must storage large volumes to ensure operations throughout the year

Storage methods for bagasse may be divided into two major classifications: compacted and bulk. Until recently, the storage methods in compacted form were practically the only systems used at pulp and paper, board, furfural and other plants, but methods in bulk and pre-dried bagasse storage have been developed more recently.

Bulk storage solves many of the shortcomings of the compacted methods, by largely eliminating bagassosis, fire hazards and space problems.

The tendency to employ bale storage is kept for those technologies that require an input of dry raw material.

The attractive alternative of the development of the 
sugarcane byproducts industry and the increasing appeal of the green energy generation in the sugar mills, forced to keep in mind that the decision-making process must be based on the careful economic analysis, that always take into account the alternatives, and never to forget when, where and how, that means a deep sense of the opportunities.

\section{The sugarcane molasses}

Sugarcane final molasses or blackstrap molasses are the mother liquor resulting from the last crystallization from which it's not possible to extract, by conventional methods, any additional sucrose. Approximately, $60 \%$ of the solids content is composed of sucrose, glucose and fructose.

The molasses composition is extremely variable, as it depends on agricultural and industrial factors, such as cane variety, maturity degree, climate behavior, culture conditions, cropping system, industrial technology, factory efficiency and never to forget that the blackstrap molasses is a co-product, being a result of the main process of sugar manufacturing.

The principal components of the molasses are water and carbohydrates; but other non-sugar compounds of organic origin, such as: carboxylic, aliphatic and olefinic acids, vitamins, proteins and phenols, are also present. The sugarcane final molasses have a fraction of mineral origin, of great importance, where more than 20 metals and non-metals are present in different proportions.

Because the sucrose extraction process in the sugar mills, gives rise to transformations of the natural components of the cane juices, increasing the range of the molasses constituents up to more than 200 substances. Of special significance because of its impacts over the utilization of the molasses, furfural and melanoidins precursors, of intense coloring and toxic effects must be mentioned.

Cuban sugarcane blackstrap molasses composition has been studied systematically for more than four decades, allowing to get a solid knowledge of their average macro composition, as shown:

\begin{tabular}{|c|c|}
\hline & $\%$ \\
\hline Water & 13.9 \\
\hline Sucrose & 36.2 \\
\hline Glucose & 4.5 \\
\hline Fructose & 6.4 \\
\hline Ashes & 12.4 \\
\hline Colloids & 9.6 \\
\hline
\end{tabular}

Non-Sugars 17.0

The inorganic fraction of the sugarcane blackstrap molasses has a special significance because of its influence over the viability of their use of them in animal feeding and as raw material for biotechnological processes. in the molasses, several cations have been identified, among which potassium, calcium and magnesium account for more than $98 \%$ of the total.

\begin{tabular}{|c|c|c|c|}
\hline Cation & $\mathrm{mg} \mathrm{kg}^{-1}$ & Cation & $\mathrm{mg} \mathrm{kg}^{-1}$ \\
\hline $\mathrm{Ag}$ & 1.01 & $\mathrm{Mg}$ & 3013 \\
\hline $\mathrm{Al}$ & 63 & $\mathrm{Mn}$ & 13.09 \\
\hline $\mathrm{Ca}$ & 8800 & $\mathrm{Na}$ & 98.3 \\
\hline $\mathrm{K}$ & 31800 & $\mathrm{Fe}$ & 519 \\
\hline $\mathrm{Cu}$ & 16.6 & $\mathrm{Zn}$ & 13.3 \\
\hline
\end{tabular}

Sugarcane final or blackstrap molasses are also rich in probiotics, being biotin and pantothenic acid the prevailing compound, the tested amounts are as follows.

\begin{tabular}{|c|c|}
\hline Vitamins & $\mathrm{mg} \mathrm{kg}^{-1}$ \\
\hline Thiamin & 1400 \\
\hline Riboflavin & 7000 \\
\hline Pantothenic acid & 5400 \\
\hline Biotin & 320 \\
\hline Inositol & 600000 \\
\hline
\end{tabular}

\section{Molasses deterioration}

Like all the co-products of the sugarcane agro-industry, molasses are produced only during the harvest season that, in most countries, lasts four or five months; it means that to guarantee the supply of the molasses throughout the year, it's unavoidable to storage them.

The experience shows that its high viscosity, the presence of carbohydrates and amino acids, plus the prevailing temperatures in the majority of the producing countries, associated with some possible wrong operation in the sugar factory, forced to take provisions to avoid the possibility of reactions leading to the deterioration of the molasses in storage.

The interactions of reducing sugars and amino acids compounds have proven to be the cause of the production of dark-colored matters referred to as melanoidins. This group of reactions is known as Maillard's reactions since he was the first one to study this phenomenon in 1912.

The Maillard reaction is highly exothermic, developed at a high rate, being particularly fast over $40^{\circ}$, driving undesirable variation in molasses composition, reports confirm that in extreme cases very dangerous evolution leads to the destruction of the storage tanks.

Molasses production - both from cane and beet- does not depend on their demand as such, because its production is subordinated to the sugar manufacturing process. In most of the producing countries, the average yield of molasses is 30$35 \%$ of sugar.

The price of molasses in the world market is influenced by a number of factors, among which supply and demand of animal feedstuff are significant, being the case the behavior of the availability and prices of grains and concentrates for cattle feeding.

The major molasses importing countries are the European 
Union, the United States, and Japan, which consume $80 \%$ of the world's molasses supply. The main exporter is Brazil, Mexico, the Philippines, and Thailand.

\section{Filter cake}

It's the residue released during the juice clarification process in the manufacturing of raw sugar. Its composition depends on a wide range of factors: type of soil, cane variety, harvesting technique (manual or mechanized), juice extraction system, system, quality of the lime employed for clarification, filtering method, etc

This co-product of sugar manufacturing contains a large amount of colloidal organic matter dispersed in the cane juice, that precipitates when it is alkalized, with the organic anions in the form of calcium salts.

It represents $13 \%$ of the milled cane, with $75 \%$ of water, $15 \%$ of the pith (used as filter aid) and remaining sugars, $7 \%$ of ash; Nitrogen is present in the form of proteins and other simple ammonia combinations, Phosphorous appears in the form of complex organic compounds, such as phospholipids and nucleoproteins and eventually as calcium phosphate as a result of the clarification process.

The filter cake is most widely used as a fertilizer taking advantage of its high nitrogen, phosphorous, calcium and organic matter content, becoming excellent support for soil sustainability in food crops.

It is also being used, with good results, for dairy cattle feed, after sun-dried. Frequently ensiled together with agricultural wastes shows an increment in its protein content.

It has proved to be an attractive raw material, through solvent extraction for the production of waxes. Various production plants in the Philippines, Cuba and India have been installed with some success.

\section{Cane crop wastes}

The sugarcane crop renders a great amount of organic matter as wastes that are successfully used as fuel in the sugar mills, but also as animal feedstuff. The beneficial actions of this waste as a soil humidity preserver and as a cover that inhibits the growth of weeds, it has been always a source of long-lasting discussions the most convenient amount of crop wastes to remain in the fields; from the practical experiences and the economic turnover, it seems to be $50 \%$.

It can be stated that when 100 tons of sugar is produced, 134 tons of total solid wastes remain in the fields, with 84.5: of tops, buds, green and dry leaves, $8.4 \%$ of cane stalks, plus $4.2 \%$ of hulks and others.

The major shortcoming in the profitable employment of the crop residues lays in its collection in the fields, during the last decade several types of equipment designed for forage handling, with minor modifications, have been successfully used in the mechanical collection and processing of crop wastes.

A significant consideration is that sugar-producing countries, with low biomass availability in their dry season (that correspond to the cane crop season), the crop wastes, could represent a suitable source of cattle feed, allowing them to avoid the recurrent impoverishment at that season, something to be discussed later on in this paper

In addition, research works done in the $90^{\text {th }}$ of the $\mathrm{XX}$ Century, developed a technology to employ the cane straw as a substrate for edible mushroom cultivation, additionally rendering an enriched spent substrate that is a rich forage for cattle.

\section{References}

1. del Olmo OA, Gutiérrez AH, Herrada MAB, Cabo OC, Polo GNA, et al. Conocimiento y potencial. The Sugarcane bagasse. Knowledge and potential.

2. del Olmo OA, Acosta YL, Sánchez FE, Santo Tomás JF. Valdés Medio ambiente y desarrollo. Conocimientos para su protección. The Environment and the Development. Knowledge to protect.

3. del Olmo OA, Balbín AC, Gutiérrez RG, Perez I, Rambla MAO, et al Aprovechamiento de las mieles de la caña de azúcar. Conocimientos y potencial. The Blackstrap Molasses, its industrial potential.

4. Cabezas EC, del Olmo OA, Herrera MC, Fernández JL, Núñez HR, et al. Tecnología azucarera. Conocimientos y práctica. Sugarcane Technology. Knowledge and Practical Aspects.

5. Senior Research Team of The Cuban Research Institute of the Sugarcane Derivatives. (ICIDCA)." Compendio de los derivados de la caña de azúcar. Compendium of the Sugarcane Byproducts.

6. Pérez I, Garrido N, Tortoló K. Energy integration for electricity generation and reducing production costs in yeast plants. Proceedings of the XXX Congres of the International Society of Sugar Cane Technologists. 2019; 30. 1522-1526. 